\title{
Helical Conformation in the CA-SP1 Junction of the Immature HIV-1 Lattice Determined from Solid State NMR of Virus-like Particles
}

\author{
Marvin J. Bayro ${ }^{1}$, Barbie K. Ganser-Pornillos ${ }^{2}$, Kaneil K. Zadrozny ${ }^{2}$, Mark Yeager ${ }^{2}$, and Robert Tycko ${ }^{\text {* }}$ \\ ${ }^{1}$ Laboratory of Chemical Physics, National Institute of Diabetes and Digestive and Kidney Diseases, National \\ Institutes of Health, Bethesda, MD 20892-0520, USA \\ ${ }^{2}$ Department of Molecular Physiology and Biological Physics, University of Virginia School of Medicine, 1340 \\ Jefferson Park Avenue, Charlottesville, VA 22908, USA
}

\section{Supporting Information, including Materials and Methods, Table S1, and Figures S1-S7}

\section{Materials and Methods}

\section{Protein expression and purification}

$\triangle \mathrm{MA}-\mathrm{CA}-\mathrm{SP} 1-\mathrm{NC}$ was cloned into pET30a (Novagen). QuikChange site-directed mutagenesis (Agilent) was used to incorporate the T371C substitution. The $\triangle \mathrm{MA}-\mathrm{CA}-\mathrm{SP} 1-\mathrm{NC}$ T371C (HIV-316) protein was expressed from freshly transformed E. coli BL21(DE3) cells, grown in minimal medium, by induction with 1 mM IPTG overnight at $25{ }^{\circ} \mathrm{C}$ in shake cultures. The minimal medium was supplemented with either ${ }^{15} \mathrm{~N}$ ammonium chloride and ${ }^{13} \mathrm{C}$ glucose for uniform ${ }^{15} \mathrm{~N},{ }^{13} \mathrm{C}$ labeling, or with ${ }^{13} \mathrm{C}$-valine, ${ }^{15} \mathrm{~N}$-leucine, and unlabeled amino acids (other than valine and leucine) for selective labeling. The protein was purified as previously described, ${ }^{1}$ except that a higher concentration of reducing agent was used during purification to improve solubility. Briefly, bacteria were harvested by centrifugation and resuspended in $50 \mathrm{mM}$ Tris, $\mathrm{pH} 8.3$, $1 \mathrm{M} \mathrm{LiCl}, 1 \mathrm{mM}$ EDTA, $100 \mathrm{mM} \beta$-mercaptoethanol ( $\beta \mathrm{ME})$ and four protease inhibitor tablets (Roche). Cells were lysed by incubation with lysozyme, supplemented with $0.3 \%(\mathrm{w} / \mathrm{v})$ deoxycholate, and sonication. Lysates were clarified by centrifugation at $18,000 \mathrm{rpm}$ for $60 \mathrm{~min}$ at $4^{\circ} \mathrm{C}$, and the protein was precipitated by addition of 0.35 equivalents $(\mathrm{v} / \mathrm{v})$ of saturated $\left(\mathrm{NH}_{4}\right)_{2} \mathrm{SO}_{4}$ solution and incubation at $4^{\mathrm{o}} \mathrm{C}$ for 10 min. The protein was recovered from the supernatant by centrifugation at $9000 \times \mathrm{g}$ for $20 \mathrm{~min}$ at $4^{\circ} \mathrm{C}$.

For anion exchange chromatography, the protein pellet was redissolved in $25 \mathrm{ml}$ of $25 \mathrm{mM}$ Tris $\mathrm{pH} 8.5$, 
$500 \mathrm{mM} \mathrm{NaCl}, 1 \mathrm{mM}$ EDTA, $20 \mathrm{mM} \beta \mathrm{M}$ ), filtered through a $0.8 \mu \mathrm{m}$ filter (Millex AA). The protein was chromatographed on a Hi-Trap Q-FF Sepharose column (GE Healthcare) and flow-through fractions containing the protein were pooled. Again, the protein was precipitated by addition of 0.35 equivalents $(\mathrm{v} / \mathrm{v})$ of saturated $\left(\mathrm{NH}_{4}\right)_{2} \mathrm{SO}_{4}$ solution and incubation at $4^{\circ} \mathrm{C}$ for $10 \mathrm{~min}$, and was recovered from the supernatant by centrifugation at $9000 \times \mathrm{g}$ for $20 \mathrm{~min}$ at $4^{\circ} \mathrm{C}$.

For cation exchange chromatography, the protein pellet was redissolved in $30 \mathrm{ml}$ of $25 \mathrm{mM} \mathrm{MOPS}$, pH 6.5, $500 \mathrm{mM} \mathrm{NaCl}, 1 \mathrm{mM}$ EDTA, $20 \mathrm{mM} \beta \mathrm{ME}$, and diluted to $75 \mathrm{ml}$ with $25 \mathrm{mM}$ MOPS, pH $6.5,500 \mathrm{mM}$ $\mathrm{NaCl}, 1 \mathrm{mM}$ EDTA, $20 \mathrm{mM} \beta \mathrm{ME}$. The protein was chromatographed on a Hi-Trap S-FF Sepharose column (GE Healthcare) and eluted at approximately $500 \mathrm{mM} \mathrm{NaCl}$ from a linear gradient of 0 to $1 \mathrm{M} \mathrm{NaCl}$. Fractions containing the protein were pooled, then recovered by addition of 0.35 equivalents $(\mathrm{v} / \mathrm{v})$ of saturated $\left(\mathrm{NH}_{4}\right)_{2} \mathrm{SO}_{4}$ solution and incubation at $4^{\circ} \mathrm{C}$ for $10 \mathrm{~min}$. Protein was recovered from the supernatant by centrifugation at $9000 \times \mathrm{g}$ for $20 \mathrm{~min}$ at $4^{\circ} \mathrm{C}$. Purified protein was then resuspended in 0.5-2 $\mathrm{ml}$ of $30 \mathrm{mM} \mathrm{MES,} \mathrm{pH} 6.0,500 \mathrm{mM}$ $\mathrm{NaCl}, 1 \mathrm{mM}$ EDTA, $20 \mathrm{mM} \beta \mathrm{ME}$ to a final concentration of $\sim 15 \mathrm{mg} / \mathrm{ml}$.

\section{Formation of virus-like particles (VLPS)}

Labeled protein with a final concentration of $\sim 15 \mathrm{mg} / \mathrm{ml}(600 \mu \mathrm{l})$ was combined with $1.5 \mathrm{M}$ tartrate (231 $\mu 1)$, and $1 \mathrm{M}$ Tris, pH $7.5(92 \mu \mathrm{l})$, then incubated at $37^{\circ} \mathrm{C}$ for $2 \mathrm{~h}$. Assembled protein was stored at room temperature. Although both wild-type $\triangle \mathrm{MA}-\mathrm{CA}-\mathrm{SP} 1-\mathrm{NC}$ and T371C mutant $\triangle \mathrm{MA}-\mathrm{CA}-\mathrm{SP} 1-\mathrm{NC}$ had similar yields of VLPs using this method for assembly, the T371C mutant produced significantly more VLPs than WT using previously reported methods for producing spheres with DNA. ${ }^{1}$ Therefore, the T371C mutant was used for all ssNMR studies. Approximately $8 \mathrm{mg}$ of VLPs were packed in each magic-angle spinning (MAS) rotor for ssNMR experiments, using centrifugation in a SW 40 Ti rotor (Beckman), with a home-built funnel device to contain the MAS rotor in the centrifuge tube.

\section{Solid state NMR spectroscopy}

NMR spectra were acquired with a Varian InfinityPlus spectrometer operating at a ${ }^{1} \mathrm{H}$ NMR frequency of 599.2 MHz, equipped with a Varian BioMAS probe with a $3.2 \mathrm{~mm}$ MAS module. Sample temperatures were maintained near $20{ }^{\circ} \mathrm{C}$ with cooled nitrogen gas. $1 \mathrm{D}{ }^{13} \mathrm{C}, 2 \mathrm{D}{ }^{13} \mathrm{C}-{ }^{13} \mathrm{C}$ and ${ }^{15} \mathrm{~N}-{ }^{13} \mathrm{C}$, and $3 \mathrm{D}{ }^{15} \mathrm{~N}-{ }^{13} \mathrm{C}-{ }^{13} \mathrm{C}$ spectra were recorded with MAS at $11.00 \mathrm{kHz}$ and with ${ }^{1} \mathrm{H}$ decoupling fields of $80-85 \mathrm{kHz}$.

The ${ }^{15} \mathrm{~N}$-filtered 1D spectrum in Fig. 1C was recorded with an NCOCX pulse sequence, i.e., ${ }^{1} \mathrm{H}^{15}{ }^{15}$ cross-polarization, followed by band-selective ${ }^{15} \mathrm{~N}-{ }^{13} \mathrm{CO}$ cross-polarization, followed by a 15 ms ${ }^{{ }^{13}} \mathrm{C}-{ }^{13} \mathrm{C}$ 
mixing period with dipolar-assisted rotational resonance (DARR). ${ }^{2}$ Aliphatic ${ }^{13} \mathrm{C}$ NMR signals are observed only for V230 in Fig. 1C, since only the V230-L231 pair is observed in this experiment due to the ${ }^{15} \mathrm{~N}-{ }^{13} \mathrm{CO}-{ }^{13} \mathrm{CX}$ correlation. (A second Val-Leu pair near the N-terminus of $\triangle$ MA-CA-SP1-NC is not observed due to flexibility of the $\triangle \mathrm{MA}$ segment.) Additional ${ }^{13} \mathrm{CO}$ signals are observed because the Leu precursor used to make the selectively labeled sample was labeled both with ${ }^{15} \mathrm{~N}$ and with ${ }^{13} \mathrm{C}$ at the carboxyl position. The unfiltered 1D spectrum of Fig. $1 \mathrm{C}$ is a ${ }^{1} \mathrm{H}-{ }^{13} \mathrm{C}$ cross-polarization spectrum, showing aliphatic signals for all valines in the sequence.

3D NCACX and NCOCX correlation experiments on $\mathrm{U}^{13} \mathrm{C},{ }^{15} \mathrm{~N}$-labeled VLPs used DARR periods of $20 \mathrm{~ms}$ and $70 \mathrm{~ms}$, respectively. These spectra were recorded with 28 and 32 complex points and $5.38 \mathrm{kHz}$ and $5.38 \mathrm{kHz}$ spectral widths in the indirect ${ }^{15} \mathrm{~N}$ and ${ }^{13} \mathrm{C}$ dimensions, respectively, with 64 scans per free-induction decay (FID) and a recycle delay of $2.2 \mathrm{~s}$, for a total acquisition time of 5.9 days per 3D spectrum. A 3D CONCA experiment was recorded with 20 and 24 complex points and $5.76 \mathrm{kHz}$ and $5.76 \mathrm{kHz}$ spectral widths in the indirect ${ }^{15} \mathrm{~N}$ and ${ }^{13} \mathrm{C}$ dimensions, respectively, with 128 scans per FID and a recycle delay of $2.2 \mathrm{~s}$, for a total acquisition time of 6.2 days. Cross-polarization times were $1 \mathrm{~ms}$ for ${ }^{1} \mathrm{H}-{ }^{15} \mathrm{~N}, 1.2 \mathrm{~ms}$ for ${ }^{1} \mathrm{H}^{13}{ }^{13} \mathrm{C}$, and $3 \mathrm{~ms}$ for ${ }^{15} \mathrm{~N}-{ }^{13} \mathrm{C}$ and ${ }^{13} \mathrm{C}-{ }^{15} \mathrm{~N}$ transfer steps. Spectra were processed with NMRPipe ${ }^{3}$ and analyzed with Sparky (T. D. Goddard and D. G. Kneller, SPARKY 3, University of California, San Francisco).

${ }^{15} \mathrm{~N}$ backbone recoupling $\left({ }^{15} \mathrm{~N}\right.$-BARE) measurements in Fig. S3 were performed with the pulse sequence described by $\mathrm{Hu}$ et al. ${ }^{4}$ in which site-specific ${ }^{15} \mathrm{~N}-{ }^{15} \mathrm{~N}$ dipolar evolution curves were extracted from crosspeak volumes in a series of 2D NCA spectra, with constant-time ${ }^{15} \mathrm{~N}-{ }^{15} \mathrm{~N}$ dipolar recoupling ${ }^{5}$ applied before the $\mathrm{t}_{1}$ period. ${ }^{15} \mathrm{~N}$-BARE measurements used $11.905 \mathrm{kHz}$ MAS, 64 complex $\mathrm{t}_{1}$ points with a $104 \mu$ s increment, and 64-256 scans per FID. Simulations of ${ }^{15} \mathrm{~N}-\mathrm{BARE}$ data were performed as described by Hu et al. ${ }^{4}$

\section{Spectral comparisons}

We compared chemical shifts and crosspeak signal amplitudes in 3D NCACX spectra of $\triangle$ MA-CA-SP1NC VLPs and tubular CA assemblies. For a given residue, the chemical shift difference $\Delta_{\mathrm{rms}, \mathrm{n}}$ was calculated as the root mean square (rms) of the differences for $\mathrm{CO}, \mathrm{C}_{\alpha}, \mathrm{C}_{\beta}$, and backbone $\mathrm{N}$ sites, weighted by appropriate scaling factors. That is,

$$
\Delta_{\mathrm{rms}, \mathrm{n}}=\sqrt{\frac{1}{4}\left[\left(\mathrm{a}_{\mathrm{CO}} \delta_{\mathrm{CO}, \mathrm{n}}\right)^{2}+\left(\mathrm{a}_{\mathrm{C} \alpha} \delta_{\mathrm{C} \alpha, \mathrm{n}}\right)^{2}+\left(\mathrm{a}_{\mathrm{C} \beta} \delta_{\mathrm{C} \beta, \mathrm{n}}\right)^{2}+\left(\mathrm{a}_{\mathrm{N}} \delta_{\mathrm{N}, \mathrm{n}}\right)^{2}\right]}
$$

where $\delta_{X, n}$ is the chemical shift difference for nucleus $X$ of residue $n$, and $a_{X}$ is an empirical scaling factor that 
accounts for the differences in variability for each type of nucleus. Scaling factors were determined as follows: First, for a given nucleus type, the chemical shift differences $\delta_{X, n}$ for all residues were tabulated and a standard deviation was calculated. Then, outliers (defined as $\delta_{X, n}$ values larger than 3.0 times the standard deviation) were removed from the list and a new standard deviation was calculated. This was done recursively until there were no remaining outliers, in order to identify the standard deviation of chemical shift differences among signals that do not vary significantly between the two types of assemblies. Using the values from Table S1, the standard deviations were $0.272,0.217,0.223$, and $0.616 \mathrm{ppm}$ for $\mathrm{X}=\mathrm{CO}, \mathrm{C} \alpha, \mathrm{C} \beta, \mathrm{N}$ respectively. These values are marked by dashed lines in Figure 4D of the main text. Scaling factors were then calculated so that the product of the scaling factor and the standard deviation was equal for all types of nuclei: $a_{C O}=0.798, a_{C \alpha}=$ $1.000, a_{C \beta}=0.974$, and $a_{N}=0.352$. Then individual values of $\Delta_{\mathrm{rms}, \mathrm{n}}$ were compared to the overall rms value of $\Delta_{\mathrm{rms}, \mathrm{n}}$ for all residues, after excluding outliers as described above. Using the calculated scaling factors, $\Delta_{\mathrm{RMS}}=$ $0.22 \mathrm{ppm}$. Residues with $\Delta_{\mathrm{rms}, \mathrm{n}}>1.5 \times \Delta_{\mathrm{RMS}}$ were considered to have significant differences in chemical shifts between the two sets of spectra, and are highlighted with star symbols in Fig. 4E of the main text.

Differences in crosspeak signal amplitudes were measured for resolved signals in NCACX spectra of VLPs and CA tubes, acquired under identical conditions, including sample temperature, external magnetic field, MAS frequency, cross-polarization times, mixing times, indirect evolution periods, numbers of direct and indirect points, and recycle delays. Although packed into identical volumes in the MAS rotors, VLP samples were somewhat less dense than CA tube samples, so that VLP samples contained approximately half the number of protein molecules as CA tube samples. Spectra of VLPs were acquired with twice as many scans, yielding an overall anticipated difference of approximately $\sqrt{2} / 2$ in signal-to-noise between the two samples. Indeed, many resolved crosspeak signals from residues with similar chemical shifts in the two samples had amplitude ratios of $0.7 \pm 0.1$ (peak height in VLP spectra divided by peak height in CA tube spectra, normalized to the same maximum signal amplitude). Residues for which crosspeak signals with had an amplitude ratio of 1.05 or greater are marked with upward-pointing triangles in Fig. 4E of the main text. Residues for which the amplitude ratio was 0.35 or less are marked with a downward-pointing triangle.

\section{Molecular modeling}

Molecular models in Fig. 4 were made with PyMOL software (The PyMOL Molecular Graphics System, Version 1.2r2 Schrödinger, LLC), using PDB files 4USN for the immature CA hexamer (Fig. 4A) and 4XFX for the mature CA hexamer (Fig. 4B) and the CA monomer (Fig. 4C). To identify residues involved in intermolecular interfaces, we used the 'Protein interfaces, surfaces and assemblies' service (PISA) at the European Bioinformatics Institute. (http://www.ebi.ac.uk/pdbe/prot int/pistart.html). For the mature NTD and 
CTD, we analyzed the full-length CA crystal structure in PDB 4XFX. ${ }^{6}$ For the immature CTD, we analyzed the CTD-SP1 crystal structure in PDB 5I4T. ${ }^{7}$ For the immature NTD and NTD-CTD interactions, we used the cryoEM-based structure in PDB $4 \mathrm{USN}^{8}$; in this case the automated analysis by PISA was supplemented with manual analysis in PyMOL to verify likely intermolecular contacts, since PDB 4USN does not include amino acid sidechains. Crystallographic symmetries were used to identify inter-hexamer interfaces.

\section{Methods references}

(1) Gross, I.; Hohenberg, H.; Wilk, T.; Wiegers, K.; Grättinger, M.; Müller, B.; Fuller, S.; Kräusslich, H. G. EMBO J. 2000, 19, 103.

(2) Takegoshi, K.; Nakamura, S.; Terao, T. Chem. Phys. Lett. 2001, 344, 631.

(3) Delaglio, F.; Grzesiek, S.; Vuister, G. W.; Zhu, G.; Pfeifer, J.; Bax, A. J. Biomol. NMR 1995, 6, 277.

(4) Hu, K. N.; Qiang, W.; Bermejo, G. A.; Schwieters, C. D.; Tycko, R. J. Magn. Reson. 2012, $218,115$.

(5) Tycko, R. J. Chem. Phys. 2007, 126, 064506.

(6) Gres, A. T.; Kirby, K. A.; KewalRamani, V. N.; Tanner, J. J.; Pornillos, O.; Sarafianos, S. G. Science 2015, 349, 99.

(7) Wagner, J. M.; Zadrozny, K.; Chrustowicz, J.; Purdy, M. D.; Yeager, M.; Ganser-Pornillos, B. K.; Pornillos, O. eLife 2016, 5, e17063.

(8) Schur, F. K. M.; Hagen, W. J. H.; Rumlova, M.; Ruml, T.; Muller, B.; Krausslich, H.-G.; Briggs, J. A. G. Nature 2015, 517, 505. 
Table S1: ssNMR chemical shifts and predicted backbone torsion angles in $\triangle \mathrm{MA}-\mathrm{CA}-\mathrm{SP} 1-\mathrm{NC}$ VLPs and CA tubes

\begin{tabular}{|c|c|c|c|c|c|c|c|c|c|c|c|c|}
\hline \multirow[t]{2}{*}{ Residue } & \multicolumn{4}{|c|}{$\begin{array}{l}\text { ssNMR chemical shifts in VLPs } \\
(\mathrm{ppm})\end{array}$} & \multicolumn{4}{|c|}{$\begin{array}{l}\text { Chemical shift differences between } \\
\text { VLPs and CA tubes (ppm) }\end{array}$} & \multicolumn{2}{|c|}{$\begin{array}{l}\text { TALOS-N torsion } \\
\text { angle predictions in } \\
\text { VLPs }\left({ }^{\circ}\right)\end{array}$} & \multicolumn{2}{|c|}{$\begin{array}{l}\text { TALOS-N } \\
\text { torsion angle } \\
\text { predictions in CA } \\
\text { tubes }\left(^{\circ}\right)\end{array}$} \\
\hline & ${ }^{13} \mathrm{CO}$ & ${ }^{13} \mathrm{C} \alpha$ & ${ }^{13} \mathrm{C} \beta$ & $\mathrm{N}$ & $\delta_{\mathrm{CO}}$ & $\delta_{\mathrm{C} a}$ & $\delta_{C \beta}$ & $\delta_{\mathrm{N}}$ & $\phi$ & $\psi$ & $\phi$ & $\psi$ \\
\hline \multicolumn{13}{|l|}{ P1 } \\
\hline \multicolumn{13}{|l|}{$\mathrm{I} 2$} \\
\hline \multicolumn{13}{|l|}{ V3 } \\
\hline \multicolumn{13}{|l|}{$\mathrm{Q} 4$} \\
\hline \multicolumn{13}{|l|}{ N5 } \\
\hline \multicolumn{13}{|l|}{ L6 } \\
\hline \multicolumn{13}{|l|}{ Q7 } \\
\hline \multicolumn{13}{|l|}{ G89 } \\
\hline \multicolumn{13}{|l|}{ Q9 } \\
\hline \multicolumn{13}{|l|}{ M10 } \\
\hline \multicolumn{13}{|l|}{ V11 } \\
\hline \multicolumn{13}{|l|}{ H12 } \\
\hline \multicolumn{13}{|l|}{ Q13 } \\
\hline A14 & 177.9 & 51.63 & & 125.2 & 0.0 & 0.01 & & 0.0 & & & & \\
\hline \multicolumn{13}{|l|}{ I15 } \\
\hline \multicolumn{13}{|l|}{ S16 } \\
\hline \multicolumn{13}{|l|}{ P17 } \\
\hline \multicolumn{13}{|l|}{ R18 } \\
\hline T19 & 176.1 & 66.67 & 67.65 & 121.3 & 0.8 & 0.51 & -0.37 & 0.4 & & & & \\
\hline \multicolumn{13}{|l|}{ L20 } \\
\hline N21 & & & & & & & & & & & & \\
\hline A22 & 180.2 & 54.46 & 17.89 & & 0.5 & -0.11 & -0.01 & & & & & \\
\hline W23 & & & & 121.1 & & & & 0.7 & & & & \\
\hline V24 & & & & & & & & & & & & \\
\hline K25 & & & & & & & & & & & & \\
\hline V26 & 177.4 & 66.39 & 31.37 & 121.1 & 0.4 & 0.98 & 0.61 & 0.3 & & & & \\
\hline V27 & & & & & & & & & & & & \\
\hline E28 & & & & & & & & & & & & \\
\hline E29 & & & & & & & & & & & & \\
\hline K30 & & & & & & & & & & & & \\
\hline A31 & & & & & & & & & & & & \\
\hline F32 & & & & & & & & & & & & \\
\hline S33 & 173.1 & 57.60 & 62.34 & 114.0 & -0.5 & 0.06 & -0.72 & \begin{tabular}{l|l}
-0.8 \\
\end{tabular} & & & & \\
\hline P34 & & & & & & & & & & & & \\
\hline E35 & & & & & & & & & & & & \\
\hline V36 & & & & & & & & & & & & \\
\hline I37 & 174.6 & 67.68 & 35.54 & 120.4 & -0.3 & 0.28 & 1.18 & 0.6 & & & & \\
\hline P38 & & & & & & & & & & & & \\
\hline
\end{tabular}




\begin{tabular}{|c|c|c|c|c|c|c|c|c|c|c|c|c|}
\hline \multicolumn{13}{|l|}{ M39 } \\
\hline F40 & 178.9 & 62.12 & 37.67 & 122.0 & 0.4 & 0.69 & -0.12 & -0.2 & -66.5 & -37.1 & -66.5 & -37.2 \\
\hline S41 & 176.0 & 61.84 & & 114.7 & 0.3 & -0.20 & & -1.0 & -65.0 & -36.6 & -64.8 & -36.9 \\
\hline A42 & 180.1 & 54.98 & 18.02 & 122.7 & $\begin{array}{c}-0.1 \\
\end{array}$ & 0.97 & -0.86 & 0.2 & -66.8 & -33.8 & -67.8 & -34.4 \\
\hline L43 & 175.0 & 54.95 & & 117.5 & -0.7 & -0.65 & & 0.3 & -74.0 & -18.3 & -71.8 & -23.4 \\
\hline S44 & 175.1 & 57.32 & 64.31 & 109.7 & 0.4 & 0.58 & 0.86 & -0.5 & $\begin{array}{l}-98.0 \\
\end{array}$ & 2.4 & -98.3 & 5.4 \\
\hline E45 & & & & & & & & & -57.9 & 130.2 & -56.6 & 128.7 \\
\hline G46 & \begin{tabular}{ll|l}
174.1 \\
\end{tabular} & 45.29 & & 116.6 & 0.2 & -0.27 & & $\begin{array}{l}-0.2 \\
\end{array}$ & 88.8 & $\begin{array}{l}-7.8 \\
\end{array}$ & 88.7 & $\begin{array}{l}-7.9 \\
\end{array}$ \\
\hline A47 & 178.0 & $\begin{array}{l}52.38 \\
\end{array}$ & 20.17 & 121.2 & -0.1 & -0.36 & 0.07 & 0.2 & -73.4 & 140.4 & -73.5 & 140.6 \\
\hline T48 & 174.7 & $\begin{array}{l}59.19 \\
\end{array}$ & 69.41 & 109.2 & 0.4 & -0.25 & 0.48 & \begin{tabular}{l|l}
-0.9 \\
\end{tabular} & -88.8 & 161.4 & -93.0 & 161.1 \\
\hline \multicolumn{13}{|l|}{ P49 } \\
\hline \multicolumn{13}{|l|}{ Q50 } \\
\hline \multicolumn{13}{|l|}{ D51 } \\
\hline \multicolumn{13}{|l|}{ L52 } \\
\hline N53 & & 56.03 & 38.48 & 117.1 & & 0.12 & 0.27 & 0.4 & -65.7 & -38.0 & -64.4 & \begin{tabular}{|c|}
-39.1 \\
\end{tabular} \\
\hline T54 & 176.0 & 66.39 & 67.70 & 121.7 & 0.0 & -0.61 & -0.21 & 1.0 & $\begin{array}{c}-67.8 \\
\end{array}$ & -37.8 & -68.0 & -38.2 \\
\hline M55 & 179.4 & 59.81 & 32.55 & 122.0 & 0.0 & -0.07 & -0.16 & 1.7 & -67.1 & -36.1 & $\begin{array}{l}-63.9 \\
\end{array}$ & -37.2 \\
\hline L56 & & & & 123.9 & & & & 0.8 & & & & \\
\hline \multicolumn{13}{|l|}{ N57 } \\
\hline \multicolumn{13}{|l|}{ T58 } \\
\hline V59 & 176.4 & 64.17 & 32.13 & 122.5 & -0.1 & 0.27 & -0.02 & 0.5 & -85.6 & -3.8 & -73.4 & 131.2 \\
\hline G60 & 174.3 & 45.18 & & 110.6 & 0.4 & 0.53 & & $\begin{array}{l}-6.9 \\
\end{array}$ & 94.6 & 5.4 & 92.5 & -10.7 \\
\hline G61 & 174.6 & 44.50 & & 109.3 & 0.4 & -0.42 & & -1.0 & -76.2 & 168.4 & -113.5 & -177.5 \\
\hline \multicolumn{13}{|l|}{ H62 } \\
\hline \multicolumn{13}{|l|}{ Q63 } \\
\hline A64 & 178.7 & 55.44 & 18.11 & 121.6 & 0.3 & -0.13 & -0.13 & -3.6 & -64.5 & -35.3 & -63.2 & $\begin{array}{l}-36.6 \\
\end{array}$ \\
\hline A65 & 179.0 & 54.37 & 18.09 & 120.7 & -0.3 & -0.44 & -0.09 & -1.5 & -66.2 & -35.2 & -66.1 & -36.0 \\
\hline M66 & & & & 119.2 & & & & 5.0 & & & & \\
\hline \multicolumn{13}{|l|}{ Q67 } \\
\hline \multicolumn{13}{|l|}{ M68 } \\
\hline L69 & 180.4 & 57.18 & 41.87 & 120.5 & -0.7 & 0.04 & 0.35 & 2.5 & & & & \\
\hline K70 & & & & 119.9 & & & & $\begin{array}{l}-0.8 \\
\end{array}$ & & & & \\
\hline \multicolumn{13}{|l|}{ E71 } \\
\hline \multicolumn{13}{|l|}{$\mathrm{T} 72$} \\
\hline \multicolumn{13}{|l|}{173} \\
\hline \multicolumn{13}{|l|}{ N74 } \\
\hline \multicolumn{13}{|l|}{ E75 } \\
\hline \multicolumn{13}{|l|}{ E76 } \\
\hline A77 & 178.5 & 54.61 & 17.53 & 124.6 & 0.0 & 0.20 & 0.11 & \begin{tabular}{|c|}
-0.1 \\
\end{tabular} & -66.7 & -37.9 & -66.4 & -38.4 \\
\hline A78 & 181.0 & 54.54 & 17.82 & 120.2 & -0.1 & 0.27 & 0.21 & 0.1 & -65.8 & -36.1 & -65.5 & -36.1 \\
\hline E79 & & & & 121.1 & & & & -0.9 & & & & \\
\hline \multicolumn{13}{|c|}{ W80 } \\
\hline \multicolumn{13}{|l|}{$\bar{D} 81$} \\
\hline R82 & & & & & & & & & & & & \\
\hline
\end{tabular}




\begin{tabular}{|c|c|c|c|c|c|c|c|c|c|c|c|c|}
\hline L83 & 176.5 & 56.90 & 42.38 & 116.0 & 0.8 & 2.01 & 0.02 & -1.7 & & & & \\
\hline H84 & & & & 118.2 & & & & 0.3 & & & & \\
\hline \multicolumn{13}{|l|}{ P85 } \\
\hline V86 & & 62.01 & 33.40 & 121.8 & & 0.04 & 0.61 & 0.0 & & & & \\
\hline \multicolumn{13}{|l|}{ H87 } \\
\hline \multicolumn{13}{|l|}{ A88 } \\
\hline \multicolumn{13}{|l|}{ G89 } \\
\hline \multicolumn{13}{|l|}{ P90 } \\
\hline \multicolumn{13}{|l|}{ I91 } \\
\hline \multicolumn{13}{|l|}{ A92 } \\
\hline \multicolumn{13}{|l|}{ P93 } \\
\hline \multicolumn{13}{|l|}{ G94 } \\
\hline \multicolumn{13}{|l|}{ Q95 } \\
\hline \multicolumn{13}{|l|}{ M96 } \\
\hline \multicolumn{13}{|l|}{ R97 } \\
\hline \multicolumn{13}{|l|}{ E98 } \\
\hline \multicolumn{13}{|l|}{ P99 } \\
\hline \multicolumn{13}{|l|}{ R100 } \\
\hline G101 & 175.6 & 48.14 & & 117.2 & -0.1 & -0.04 & & -0.4 & -57.7 & -39.0 & -62.1 & -36.8 \\
\hline S102 & 176.9 & 60.58 & 61.84 & 115.5 & 0.3 & 0.10 & 0.17 & -0.1 & -64.1 & -34.6 & $\begin{array}{l}-64.9 \\
\end{array}$ & -32.7 \\
\hline D103 & 179.5 & 56.39 & 41.00 & 123.6 & 0.0 & -0.07 & -0.20 & 0.1 & $\begin{array}{l}-71.0 \\
\end{array}$ & -35.2 & -75.2 & -33.9 \\
\hline I104 & 172.6 & 65.44 & 36.64 & 126.5 & 0.2 & -0.03 & 0.14 & -0.1 & $\begin{array}{l}-64.0 \\
\end{array}$ & -32.2 & $\begin{array}{l}-62.0 \\
\end{array}$ & -37.5 \\
\hline A105 & 177.0 & 50.17 & 18.45 & 112.7 & 0.1 & -0.05 & 0.06 & $\begin{array}{l}-0.2 \\
\end{array}$ & -94.8 & 4.3 & -84.5 & \begin{tabular}{|l|}
-7.9 \\
\end{tabular} \\
\hline G106 & 173.1 & 45.29 & & 103.5 & -0.2 & 0.13 & & 0.4 & -70.9 & -15.5 & 85.1 & 29.6 \\
\hline T107 & 176.9 & 63.77 & 68.67 & 114.3 & 0.0 & 0.11 & 0.08 & 0.3 & -74.4 & -23.3 & -72.5 & -25.2 \\
\hline T108 & 173.1 & 60.57 & 69.02 & 106.9 & 0.1 & -0.03 & -0.02 & 0.1 & -106.6 & 0.8 & $\begin{array}{l}-94.1 \\
\end{array}$ & 1.7 \\
\hline S109 & 173.6 & 53.85 & 67.08 & 112.4 & -0.1 & 0.07 & 0.49 & -0.7 & -124.9 & 159.8 & -123.9 & 159.8 \\
\hline T110 & 175.7 & 58.97 & 71.44 & 112.4 & 0.2 & -0.05 & 0.48 & -1.0 & -115.1 & 165.6 & -117.7 & 165.8 \\
\hline L111 & & 57.92 & 40.86 & 123.4 & & 0.24 & 0.41 & -0.2 & -58.7 & -35.7 & -60.6 & -37.2 \\
\hline \multicolumn{13}{|l|}{ Q112 } \\
\hline \multicolumn{13}{|l|}{ E113 } \\
\hline \multicolumn{13}{|l|}{ Q114 } \\
\hline I115 & & 64.99 & 37.29 & 119.1 & & -0.39 & -1.22 & 0.0 & $\begin{array}{l}-65.9 \\
\end{array}$ & -38.4 & -65.4 & -39.8 \\
\hline G116 & 175.9 & 46.91 & & 111.8 & 0.2 & 0.04 & & 0.2 & -62.0 & -41.5 & -62.6 & -38.4 \\
\hline W117 & 178.9 & 62.61 & 26.82 & 122.2 & 0.3 & 0.75 & -0.48 & -0.1 & -66.6 & -36.0 & -68.1 & -36.3 \\
\hline M118 & 177.6 & 59.14 & 32.18 & 115.4 & 0.4 & -0.17 & -2.52 & -1.5 & -68.2 & -30.3 & -67.9 & -33.3 \\
\hline T119 & 173.8 & 60.68 & 69.90 & 105.9 & 0.4 & 0.04 & 0.29 & 0.7 & -96.7 & 2.4 & -95.5 & -1.0 \\
\hline H120 & & & & 124.6 & & & & -0.4 & -67.4 & 136.2 & -67.0 & 137.1 \\
\hline N121 & 172.0 & 48.83 & 40.15 & 120.2 & -0.1 & 0.01 & 0.49 & 0.4 & -120.4 & 132.3 & -124.0 & 135.5 \\
\hline \multicolumn{13}{|l|}{ P122 } \\
\hline \multicolumn{13}{|l|}{ P123 } \\
\hline I124 & & 59.06 & 38.28 & 122.4 & & 0.03 & 0.32 & -1.4 & & & & \\
\hline \multicolumn{13}{|l|}{$\mathrm{P} 125$} \\
\hline V126 & 176.6 & 65.48 & 30.67 & 116.4 & 0.1 & 0.13 & 0.07 & 0.1 & -59.1 & -35.3 & -58.9 & -34.3 \\
\hline
\end{tabular}




\begin{tabular}{|c|c|c|c|c|c|c|c|c|c|c|c|c|}
\hline G127 & 174.4 & 47.00 & & 107.3 & -0.3 & 0.09 & & -0.3 & -58.8 & -41.3 & -61.0 & -42.7 \\
\hline E128 & & & & 122.9 & & & & 0.1 & & & & \\
\hline \multicolumn{13}{|l|}{ I129 } \\
\hline \multicolumn{13}{|l|}{ Y130 } \\
\hline \multicolumn{13}{|l|}{ K131 } \\
\hline \multicolumn{13}{|l|}{ R132 } \\
\hline \multicolumn{13}{|l|}{ W133 } \\
\hline I134 & & 64.99 & 38.10 & 121.1 & & 0.08 & 0.08 & 1.4 & -64.0 & -39.7 & -65.1 & -39.1 \\
\hline I135 & 177.5 & 66.81 & 37.73 & 122.3 & 0.1 & 0.76 & 0.35 & 0.0 & -64.5 & -40.7 & -67.2 & -37.5 \\
\hline L136 & 181.1 & 58.01 & 40.31 & 122.0 & 0.3 & -0.44 & -0.95 & -0.6 & -65.9 & -36.5 & -65.2 & -38.1 \\
\hline G137 & 175.3 & 46.88 & & 110.8 & -0.3 & -0.44 & & 3.0 & -63.3 & -39.0 & -63.5 & -40.1 \\
\hline L138 & & 58.33 & 41.71 & 122.8 & & 0.62 & -0.16 & -1.4 & -68.6 & -35.0 & -68.2 & -35.6 \\
\hline \multicolumn{13}{|l|}{ N139 } \\
\hline \multicolumn{13}{|l|}{ K140 } \\
\hline \multicolumn{13}{|l|}{ I141 } \\
\hline \multicolumn{13}{|l|}{ V142 } \\
\hline \multicolumn{13}{|l|}{ R143 } \\
\hline \multicolumn{13}{|l|}{ M144 } \\
\hline \multicolumn{13}{|l|}{ Y145 } \\
\hline \multicolumn{13}{|l|}{ S146 } \\
\hline \multicolumn{13}{|l|}{ P147 } \\
\hline \multicolumn{13}{|l|}{ T148 } \\
\hline S149 & 174.7 & 57.57 & 64.77 & 118.2 & -2.2 & 1.24 & 0.81 & -2.2 & -91.9 & 128.6 & -93.3 & 127.3 \\
\hline I150 & 178.0 & 58.79 & 38.42 & 121.7 & 3.1 & -1.72 & -0.68 & -7.8 & -106.5 & 4.4 & -107.4 & 130.2 \\
\hline L151 & 177.4 & 57.38 & 40.47 & 119.1 & -1.9 & -0.46 & -0.49 & 0.5 & -66.3 & -24.8 & -69.7 & -33.2 \\
\hline D152 & 176.2 & 53.97 & 41.72 & 114.9 & 0.6 & 0.18 & -0.14 & -1.7 & -93.8 & -0.7 & -90.7 & -4.1 \\
\hline I153 & 174.1 & 58.60 & 33.56 & 121.3 & 0.6 & -0.16 & -1.78 & -1.9 & -84.8 & 123.0 & -91.4 & 125.5 \\
\hline R154 & & & & 126.0 & & & & -0.4 & -112.1 & 140.7 & -115.4 & 136.8 \\
\hline Q155 & 175.8 & 55.26 & 27.11 & 127.5 & -0.9 & -0.06 & 0.22 & -1.0 & -66.9 & 136.3 & -66.8 & 133.0 \\
\hline G156 & 173.3 & 45.16 & & 117.4 & 0.3 & 0.32 & & -0.6 & -78.9 & 166.2 & -82.2 & 167.5 \\
\hline \multicolumn{13}{|l|}{ P157 } \\
\hline \multicolumn{13}{|l|}{ K158 } \\
\hline E159 & 174.9 & 53.38 & 31.87 & 127.2 & 0.7 & 0.31 & -0.20 & 0.9 & & & & \\
\hline \multicolumn{13}{|l|}{ P160 } \\
\hline F161 & 177.1 & 62.72 & 38.37 & 128.5 & 0.3 & 0.54 & -0.89 & -0.1 & & & & \\
\hline \multicolumn{13}{|l|}{ R162 } \\
\hline \multicolumn{13}{|l|}{ D163 } \\
\hline \multicolumn{13}{|l|}{ Y164 } \\
\hline V165 & & & & & & & & & & & & \\
\hline D166 & & & & & & & & & & & & \\
\hline R167 & & & & & & & & & & & & \\
\hline F168 & 177.0 & 62.43 & 38.68 & 124.9 & 0.3 & 0.31 & -0.85 & -0.2 & -64.2 & -41.1 & -66.3 & -37.3 \\
\hline Y169 & 178.2 & 62.95 & 37.40 & 118.2 & -0.9 & -0.46 & -0.38 & 2.2 & -66.0 & -34.3 & -62.7 & -37.5 \\
\hline K170 & & & & & & & & & & & & \\
\hline
\end{tabular}




\begin{tabular}{|c|c|c|c|c|c|c|c|c|c|c|c|c|}
\hline $\mathrm{T} 171$ & 176.6 & 66.77 & 68.56 & 118.2 & 0.7 & 0.80 & -1.77 & 3.1 & & & & \\
\hline L172 & & & & 123.4 & & & & -0.5 & & & & \\
\hline \multicolumn{13}{|l|}{ R173 } \\
\hline A174 & & 53.05 & 17.31 & 124.6 & & 0.44 & 0.11 & -0.1 & & & & \\
\hline \multicolumn{13}{|l|}{ E175 } \\
\hline \multicolumn{13}{|l|}{ Q176 } \\
\hline A177 & & 52.03 & 19.36 & 118.6 & & 0.03 & 0.37 & -1.1 & & & & \\
\hline \multicolumn{13}{|l|}{ S178 } \\
\hline \multicolumn{13}{|l|}{ Q179 } \\
\hline \multicolumn{13}{|l|}{ E180 } \\
\hline \multicolumn{13}{|l|}{ V181 } \\
\hline \multicolumn{13}{|l|}{ K182 } \\
\hline \multicolumn{13}{|l|}{ N183 } \\
\hline W184 & 179.2 & 62.12 & 27.15 & 122.5 & 0.1 & 0.29 & -1.07 & -0.9 & -63.3 & -38.2 & -63.1 & -40.2 \\
\hline M185 & & 60.25 & 32.58 & 115.7 & & 0.84 & -0.10 & -1.2 & -66.8 & -37.8 & -68.7 & -36.0 \\
\hline T186 & 173.2 & & & & & & & & & & & \\
\hline \multicolumn{13}{|l|}{ E187 } \\
\hline T188 & 173.7 & 62.60 & 70.11 & 110.2 & -0.4 & -0.71 & 0.96 & 1.0 & -66.4 & -37.7 & -67.4 & -37.7 \\
\hline L189 & & 58.17 & 40.96 & 122.5 & & -0.28 & 1.05 & & -66.3 & -38.6 & -67.0 & -38.7 \\
\hline \multicolumn{13}{|l|}{ L190 } \\
\hline V191 & & 65.49 & 31.71 & 117.0 & & 0.47 & -0.12 & 0.8 & & & & \\
\hline \multicolumn{13}{|l|}{ Q192 } \\
\hline N193 & 175.6 & 52.62 & 37.91 & 114.8 & 0.5 & 0.33 & -0.09 & -0.7 & -93.8 & -3.2 & -95.9 & -1.5 \\
\hline A194 & 175.1 & 51.70 & 18.64 & 125.6 & -0.1 & 0.12 & 0.10 & -0.1 & -71.8 & 139.8 & -72.6 & 136.1 \\
\hline N195 & & 51.35 & 34.85 & 118.9 & & 0.04 & -1.01 & -1.5 & -69.6 & 150.3 & -71.1 & 147.2 \\
\hline \multicolumn{13}{|l|}{ P196 } \\
\hline \multicolumn{13}{|l|}{ D197 } \\
\hline C198 & 179.2 & 60.38 & 28.81 & 118.9 & 0.7 & 0.82 & -6.22 & 1.8 & -68.4 & -36.8 & -72.5 & -31.1 \\
\hline K199 & & 60.42 & 31.83 & 120.8 & & -0.28 & -0.31 & -2.0 & -64.3 & -37.8 & -64.1 & -39.0 \\
\hline T200 & 176.4 & 66.17 & 68.84 & 113.3 & 0.4 & -0.26 & 0.04 & 0.2 & -66.9 & -37.4 & -66.5 & -37.9 \\
\hline $\mathrm{I} 201$ & 178.5 & 64.44 & 38.53 & 123.6 & 0.3 & 0.21 & 0.51 & -0.5 & -66.9 & -41.2 & -66.7 & -39.0 \\
\hline \multicolumn{13}{|l|}{ L202 } \\
\hline \multicolumn{13}{|l|}{ K203 } \\
\hline A204 & 178.6 & 53.20 & 18.20 & 120.7 & 0.5 & 0.05 & 0.01 & -0.5 & -69.1 & -21.7 & -69.3 & -19.6 \\
\hline L205 & 178.3 & 55.95 & 42.16 & 119.3 & -0.4 & -0.31 & -0.11 & 1.2 & -78.0 & -15.5 & -78.2 & -16.7 \\
\hline G206 & 171.8 & 44.16 & & 105.4 & 0.4 & 0.04 & & 0.3 & 92.2 & 179.8 & 91.0 & -179.7 \\
\hline \multicolumn{13}{|l|}{ P207 } \\
\hline G208 & 174.7 & 45.28 & & 110.6 & 0.2 & 0.15 & & -0.4 & 90.8 & -6.9 & 89.9 & -8.1 \\
\hline A209 & 177.7 & 52.12 & 19.64 & 124.2 & 0.2 & 0.08 & 0.13 & -0.4 & -74.5 & 136.7 & -75.5 & 134.2 \\
\hline $\mathrm{T} 210$ & 175.2 & 60.06 & 71.10 & 114.5 & 0.1 & 0.21 & 0.93 & -0.2 & -102.6 & 161.8 & -93.8 & 152.3 \\
\hline L211 & 179.0 & & 40.48 & 123.5 & -0.2 & & 0.28 & -2.7 & -60.7 & -35.1 & -60.9 & -35.5 \\
\hline E212 & & & & 121.0 & & & & 0.6 & & & & \\
\hline \multicolumn{13}{|l|}{ E213 } \\
\hline M214 & & & & & & & & & & & & \\
\hline
\end{tabular}




\begin{tabular}{|l|l|l|l|l|l|l|l|l|l|l|l|l|}
\hline M215 & & & & & & & & & & & & \\
\hline T216 & 175.8 & 65.76 & 70.00 & 118.6 & & -0.02 & 1.36 & 2.6 & -67.7 & -35.6 & -64.4 & -35.8 \\
\hline A217 & 179.8 & 54.69 & 18.83 & 123.2 & 0.9 & 0.00 & 0.28 & -1.1 & -62.518 & -32.066 & -66.6 & -29.5 \\
\hline C218 & 175.6 & 59.54 & 28.28 & 111.9 & 1.3 & 3.07 & -11.90 & 0.9 & -81.161 & -15.065 & -81.6 & -8.3 \\
\hline Q219 & 173.4 & 59.02 & 29.83 & 126.6 & & & & & -62.389 & -32.507 & & \\
\hline G220 & 176.4 & 43.57 & & 98.65 & & & & & 109.082 & 6.494 & & \\
\hline V221 & 177.4 & 64.34 & 29.94 & 123.7 & & & & & -63.854 & 132.785 & & \\
\hline G222 & 174.5 & 45.02 & & 119.1 & & & & & 91.138 & 0.591 & & \\
\hline G223 & 171.3 & 44.39 & & 109.6 & & & & & -100.25 & 170.319 & & \\
\hline P224 & 179.0 & 65.71 & 31.94 & 133.5 & & & & & -59.751 & -39.881 & & \\
\hline G225 & 175.5 & 47.14 & & 111.6 & & & & & -62.742 & -43.487 & & \\
\hline H226 & 175.1 & 59.09 & 28.56 & 126.3 & & & & & -64.716 & -38.568 & & \\
\hline K227 & 176.4 & 56.95 & 30.59 & 118.5 & & & & & -65.453 & -34.027 & & \\
\hline A228 & 178.7 & 53.47 & 17.61 & 121.3 & & & & & -67.1 & -37.035 & & \\
\hline R229 & 180.3 & 60.11 & 28.63 & 119.7 & & & & & -66.343 & -38.805 & & \\
\hline V230 & 178.1 & 66.82 & 30.58 & 124.5 & & & & & -66.351 & -39.397 & & \\
\hline L231 & 174.0 & 57.73 & 40.45 & 121.9 & & & & & -66.061 & -38.469 & & \\
\hline A232 & 175.44 & 54.28 & 18.61 & 124.6 & & & & & -63.155 & -37.559 & & \\
\hline E233 & 179.04 & 59.07 & 26.78 & 117.8 & & & & & -67.825 & -36.868 & & \\
\hline A234 & 178.04 & 54.51 & 19.1 & 120.2 & & & & & -65.947 & -37.63 & & \\
\hline M235 & 178.44 & 59.3 & 29.29 & 119.1 & & & & & -67.589 & -35.422 & & \\
\hline S236 & 178.64 & 57.61 & 60.2 & 121.3 & & & & & -67.322 & -35.464 & & \\
\hline Q237 & 176.44 & 56.03 & 28.79 & 116.1 & & & & & -68.153 & -34.296 & & \\
\hline V238 & 178.44 & 64.56 & 30 & 123.5 & & & & & -67.164 & -37.858 & & \\
\hline C239 & 176.54 & 62.89 & 28.02 & 115.8 & & & & & -64.114 & -34.109 & & \\
\hline N240 & 176.44 & 54.59 & & 123.1 & & & & & -60.389 & -45.958 & & \\
\hline P241 & & 62.35 & & 138.5 & & & & & & & & \\
\hline
\end{tabular}



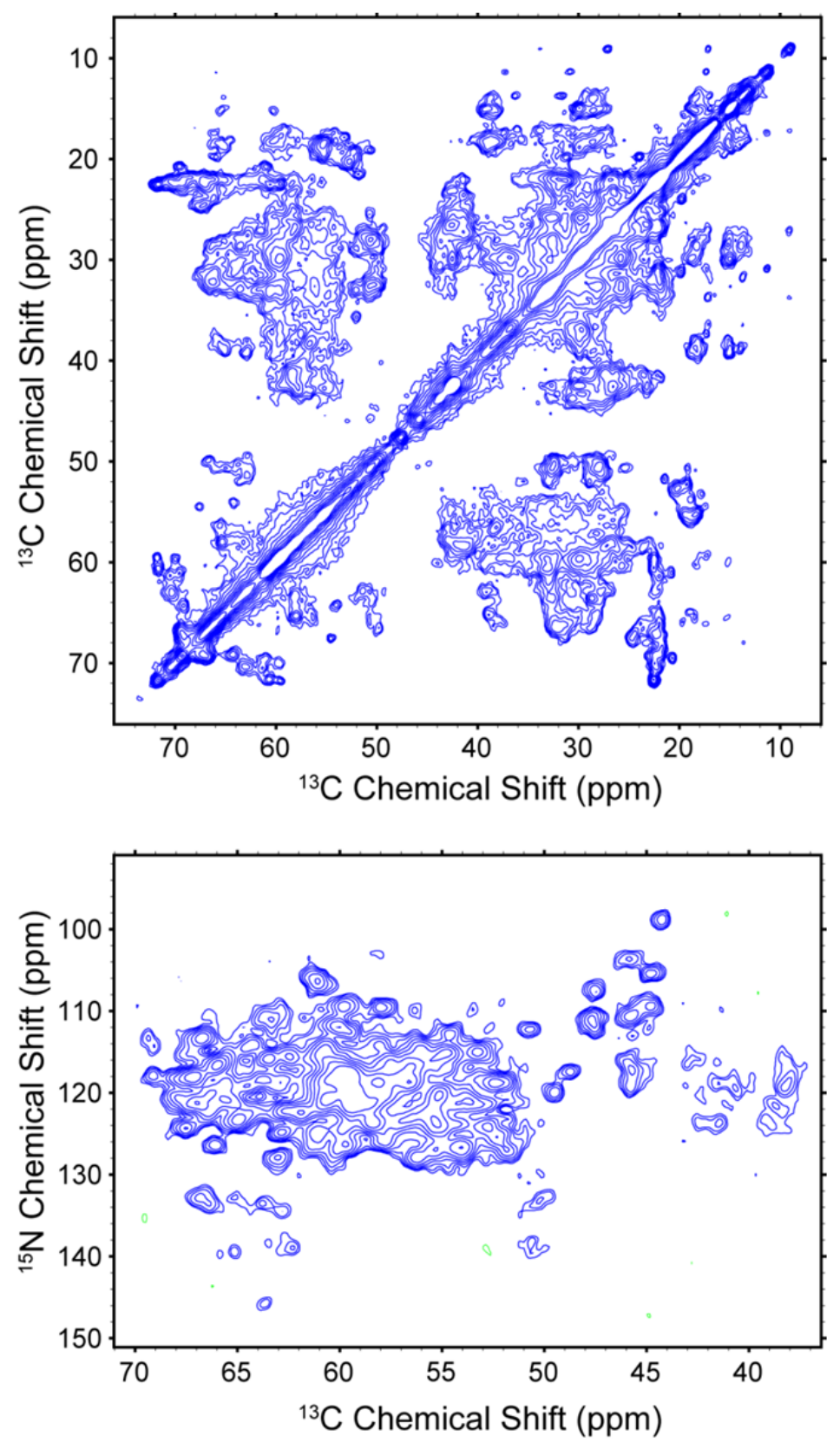

Figure S1. 2D ${ }^{13} \mathrm{C}-{ }^{13} \mathrm{C}$ and ${ }^{15} \mathrm{~N}-{ }^{13} \mathrm{C}$ correlation spectra of VLPs formed by $\triangle \mathrm{MA}-\mathrm{CA}-\mathrm{SP} 1-\mathrm{NC}$. All spectra were recorded at 599.2 $\mathrm{MHz}{ }^{1} \mathrm{H} \mathrm{NMR}$ frequency, with $11.0 \mathrm{kHz}$ MAS. Contour levels increase by successive factors of 1.4. 

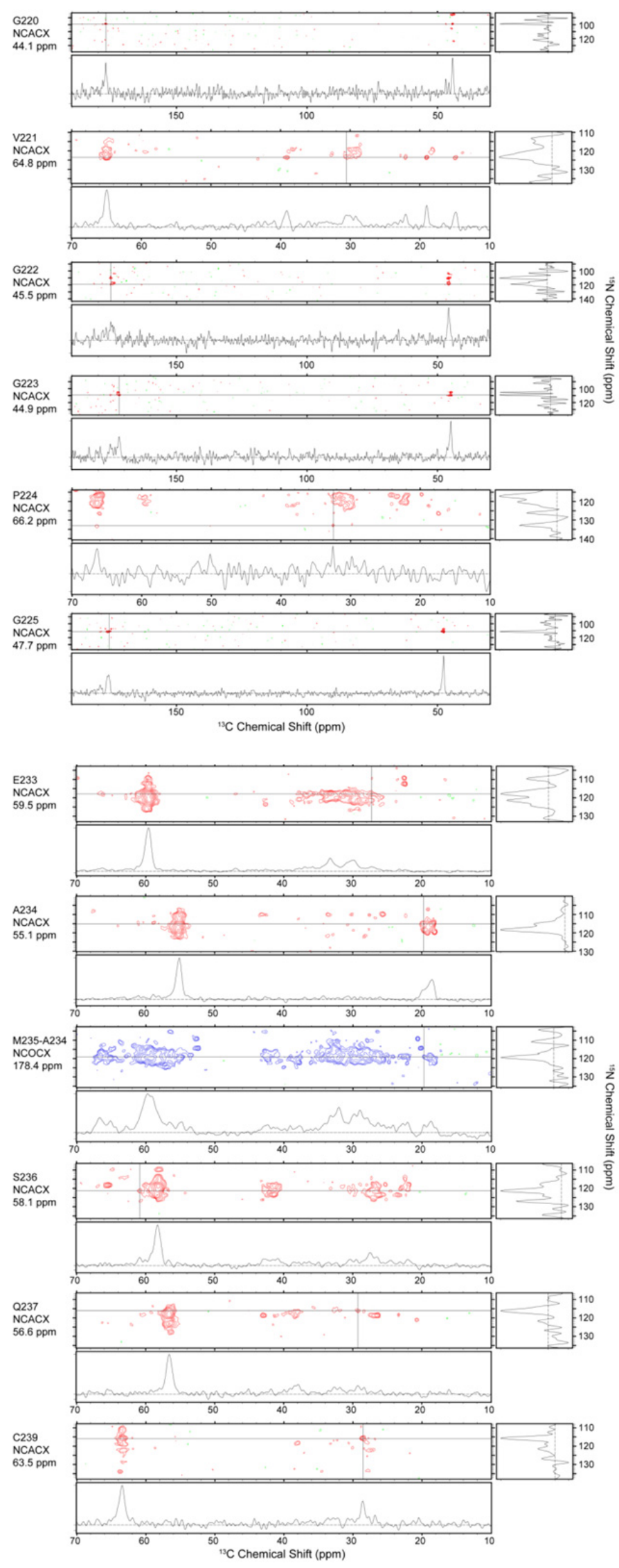
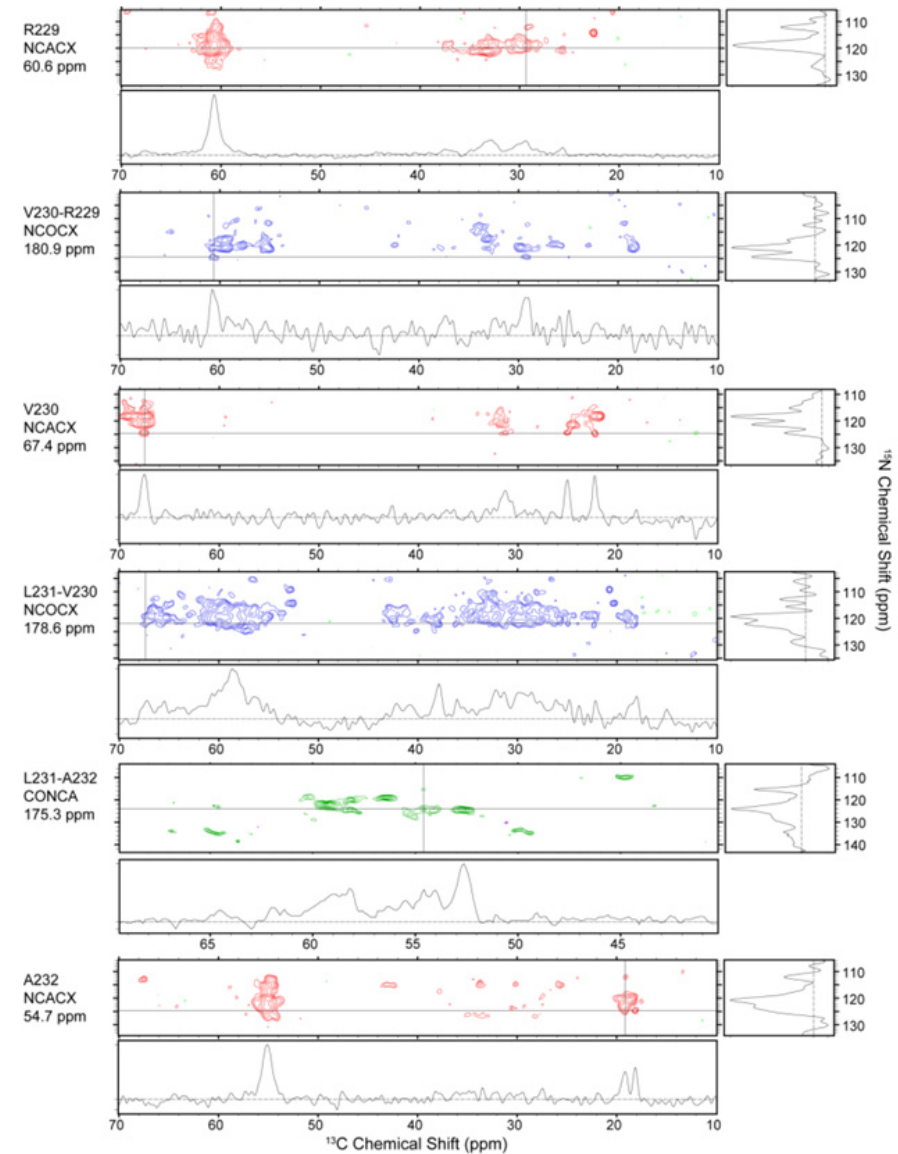

Figure S2. Examples of 2D planes and 1D slices from $3 \mathrm{D}$ spectra of uniformly ${ }^{15} \mathrm{~N},{ }^{13} \mathrm{C}$-labeled VLPs for various residues around the CA-SP1 junction. Planes are labeled by the $13 \mathrm{C}$ chemical shift of the $\mathrm{CA}(\mathrm{i})$ or $\mathrm{CO}(\mathrm{i})$ resonance in $\mathrm{N}(\mathrm{i})$ $\mathrm{CA}(\mathrm{i})-\mathrm{CX}(\mathrm{i}), \quad \mathrm{N}(\mathrm{i}+1)-\mathrm{CO}(\mathrm{i})-\mathrm{CX}(\mathrm{i})$, and $\mathrm{CO}(\mathrm{i})-$ $\mathrm{N}(\mathrm{i}+1)-\mathrm{CA}(\mathrm{i}+1) \quad 3 \mathrm{D}$ sequential correlation experiments. Contour levels increase by successive factors of 1.4 . 


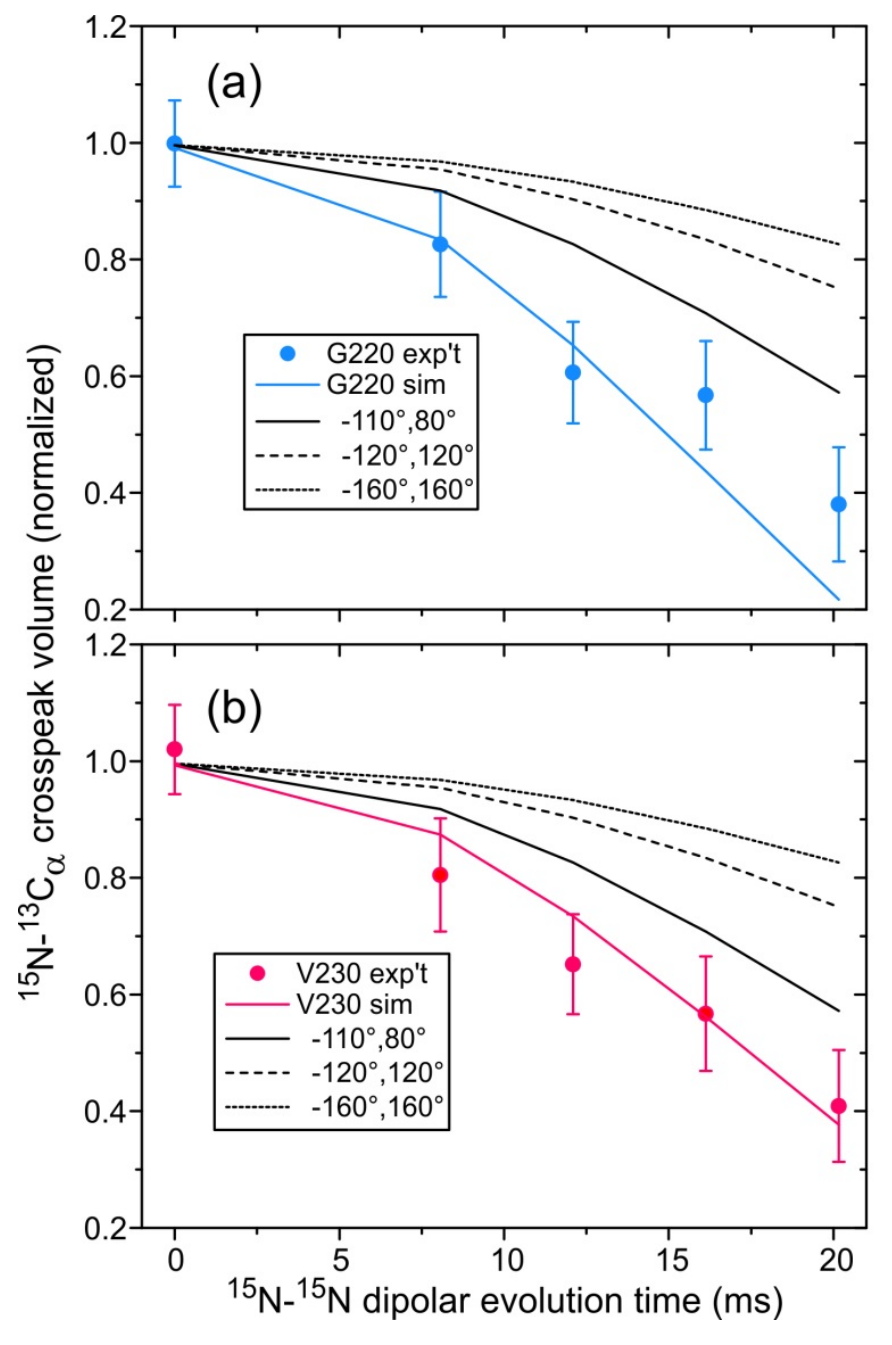

(c)

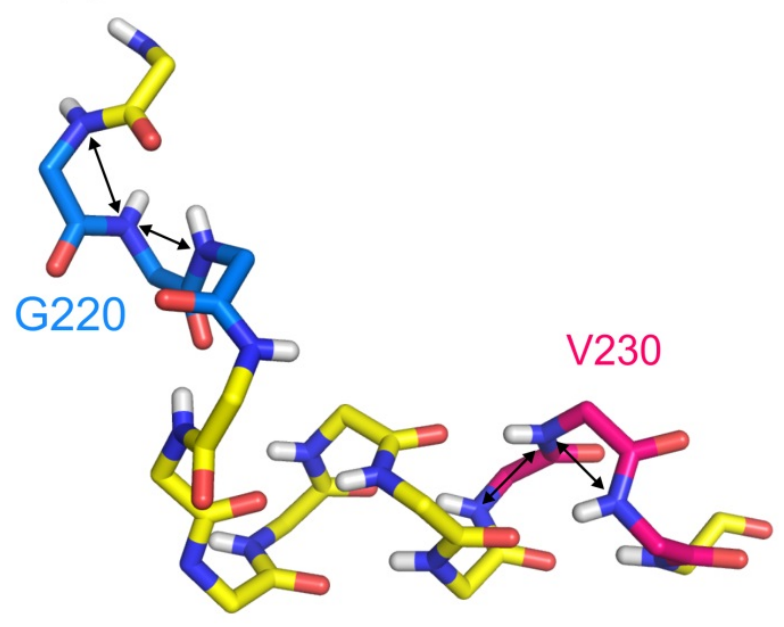

Figure S3. Measurements of site-specific ${ }^{15} \mathrm{~N}-{ }^{15} \mathrm{~N}$ dipole-dipole couplings in uniformly ${ }^{15} \mathrm{~N},{ }^{13} \mathrm{C}$-labeled VLPs, using the ${ }^{15} \mathrm{~N}$-BARE ssNMR technique. (a,b) ${ }^{15} \mathrm{~N}$-BARE data for G220 and V230, which have resolved crosspeaks in the 2D NCA spectra from which the dipolar evolution curves are extracted. Data for residue $\mathrm{k}$ depend on distances and directions from the backbone ${ }^{15} \mathrm{~N}$ site of residue $\mathrm{k}$ to backbone ${ }^{15} \mathrm{~N}$ sites of residues $\mathrm{k}-1$ and $\mathrm{k}+1$. Color-coded lines are numerical simulations using coordinates from PDB file 5I4T, a crystal structure in which a CTD-SP1 construct forms an immature-like lattice. Solid, dashed, and dotted black lines are simulations for an ideal peptide chain with the indicated backbone $\phi, \psi$ angles. These simulations illustrate the dependence of ${ }^{15} \mathrm{~N}$-BARE data on backbone conformation. (c) Conformation of residues 218-232 in PDB file 5I4T, with carbon atoms of residues 219-221 and 229-231 colored to correspond with ${ }^{15} \mathrm{~N}$-BARE data in panels $\mathrm{a}$ and $\mathrm{b}$. Distances among relevant ${ }^{15} \mathrm{~N}$ sites are indicated by arrows. 

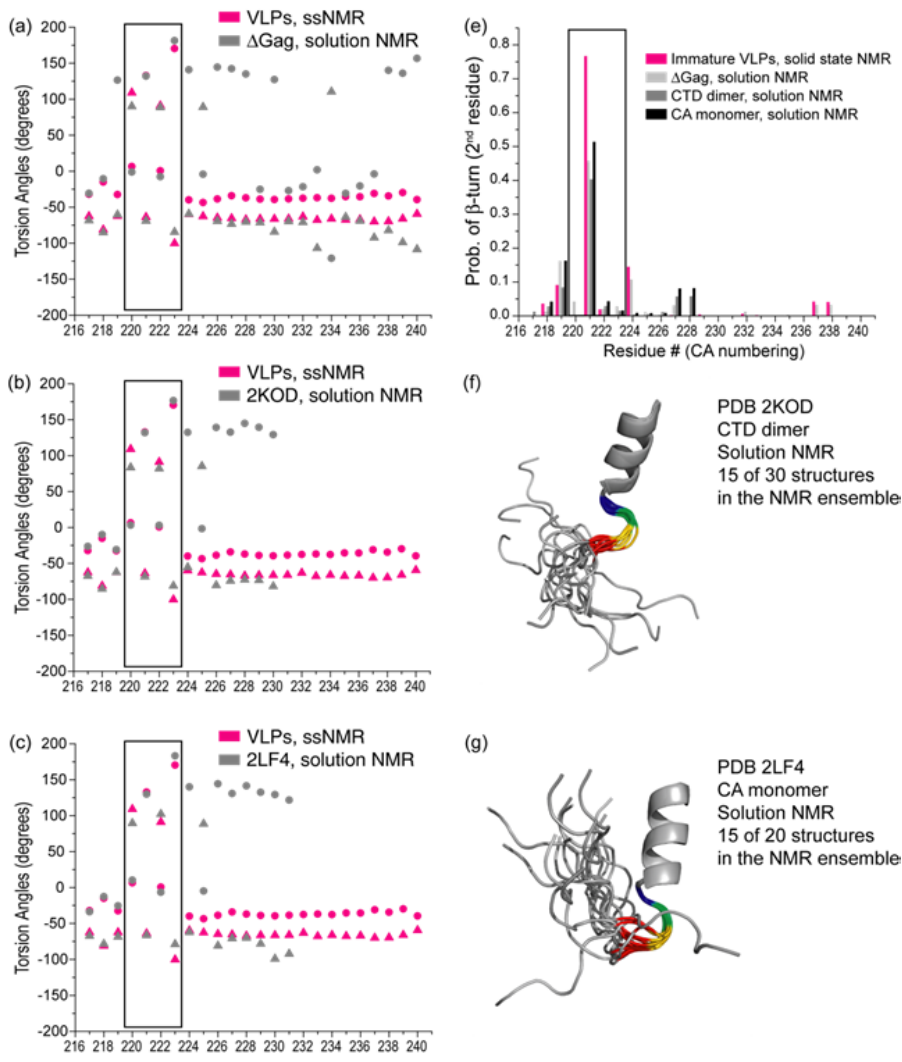

(g)
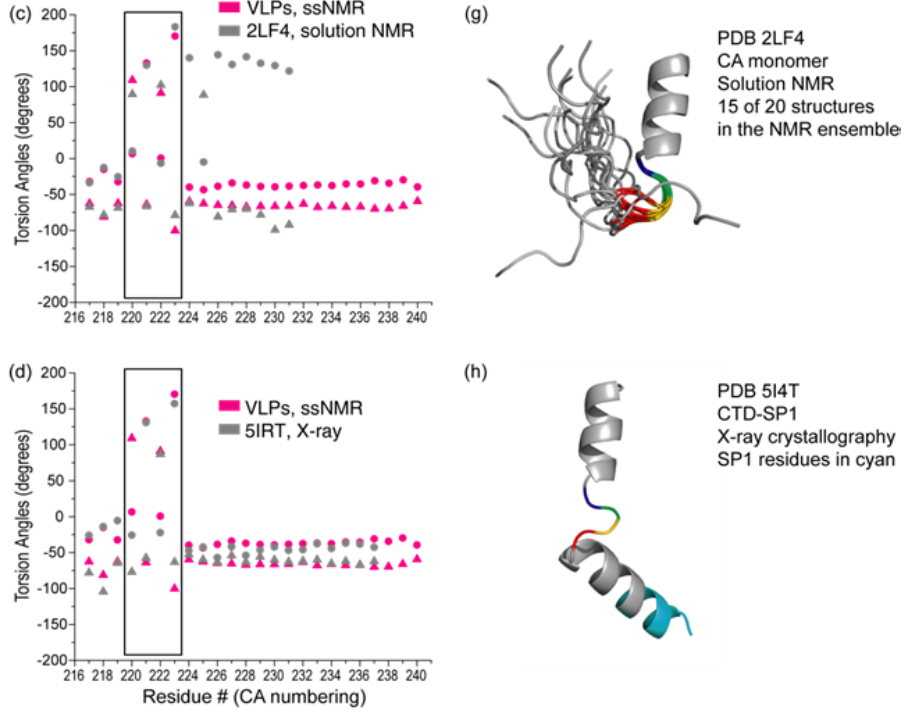

(h)

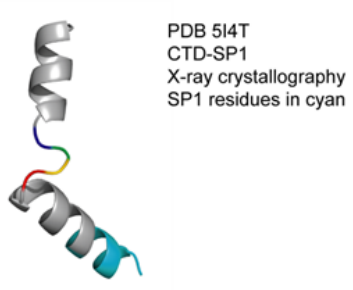

Figure S4. ssNMR-based torsion angle predictions in the CA-SP1 junction of $\triangle \mathrm{MA}-\mathrm{CA}-\mathrm{SP} 1-\mathrm{NC}$ VLPs and comparison to previous studies. (a-c) Predictions of backbone $\phi$ (triangles) and $\psi$ (circles) angles from TALOS-N, based on ssNMR chemical shifts from VLPs (pink) and solution NMR chemical shifts (gray) of MA-CA-SP1-NC ( $\triangle \mathrm{Gag}, \mathrm{BMRB} 25532)$, CTD dimers (PDB 2KOD), and CA monomers (PDB 2LF4), respectively. (d) Comparison with torsion angles from the crystal structure of CTD-SP1 (PDB 5I4T). The box in panels a-d highlights the segment G220-V221-G222-G223, which presents similar predicted torsion angles in all cases, consistent with a type II $\beta$-turn. (e) Chemical shift-based analysis with the MICS program predicts a high probability of a type II $\beta$-turn in VLPs, and also a modest probability in all three solution NMR constructs. $(\mathrm{f}, \mathrm{g})$ Cartoon representations of subsets of the solution NMR structure bundles for residues 210-231 in PDB files 2KOD and 2FL4, which display a turn-like motif in residues 220-223 before the disordered C-terminal segment. (h) Residues 210-238 in PDB 5I4T, with residues from SP1 residues cyan. 


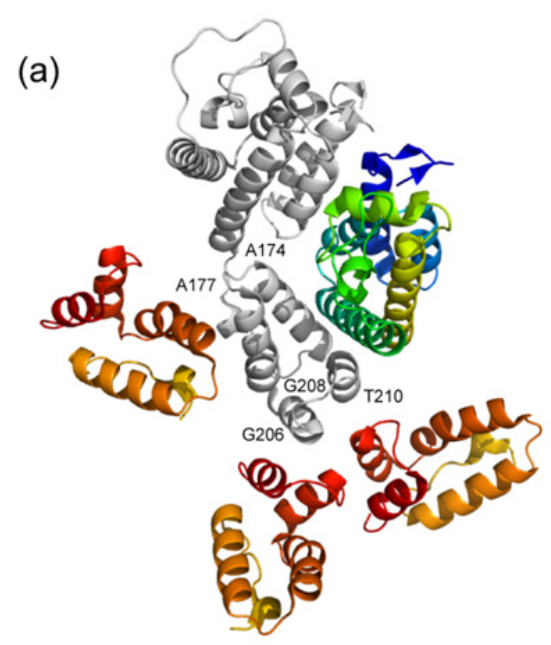

(c)

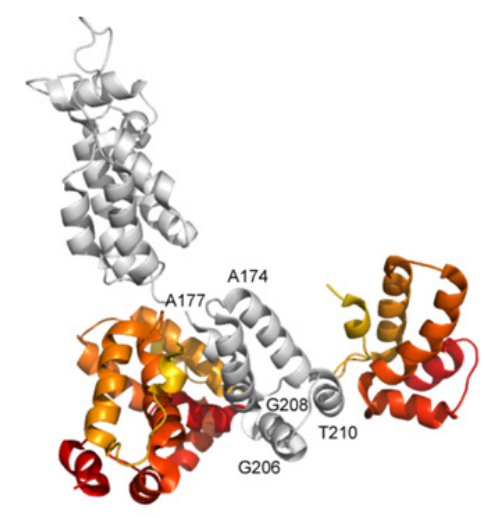

(b)

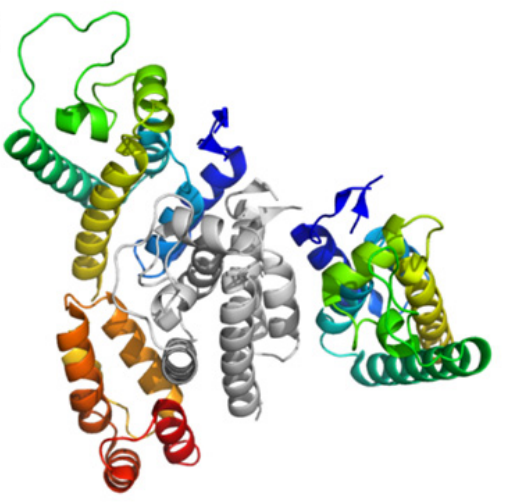

(d)

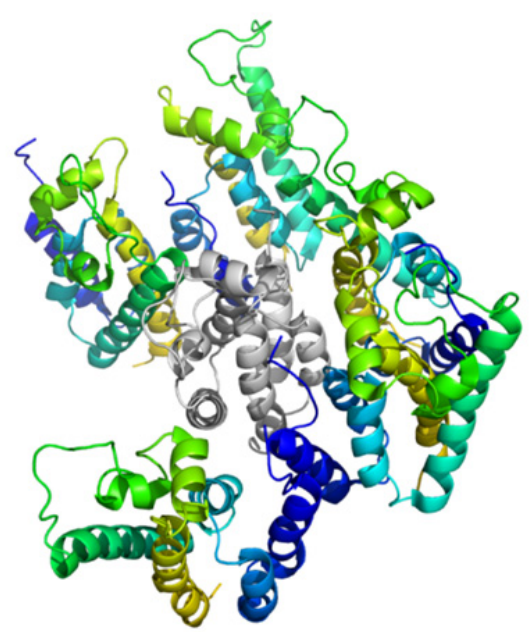

Figure S5. Intermolecular interactions between CA proteins in mature $(a, b)$ and immature (c,d) capsid lattices. A central CA protein is shown in gray, while surrounding proteins are rainbow-colored, with NTD in blue and green and CTD in orange and red. Panels a and c show the intermolecular contacts around a central CTD domain in both types of assemblies. Residues that make contacts in the mature lattice (a) but not the immature lattice (c) and exhibit differences in ssNMR spectra are labeled (see main text and Fig. S5). Panels b and d show the intermolecular contacts around a central NTD domain in both types of assemblies. 

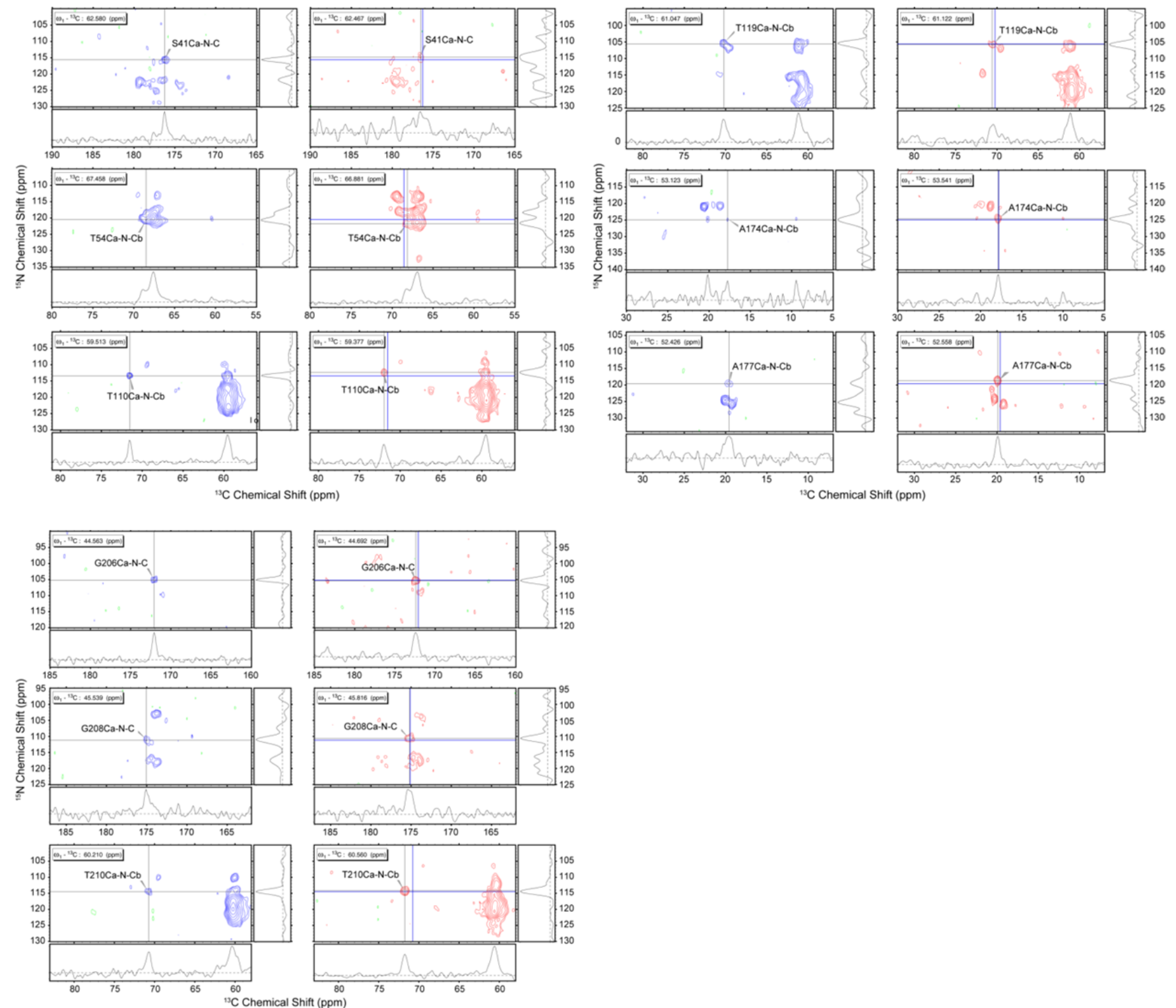

Figure S6. Comparison of chemical shifts and signal intensities in ssNMR spectra of CA tubes (blue) and $\triangle$ MA-CA-SP1-NC VLPs (red). 2D planes from 3D NCACX spectra that contain crosspeak signals from the indicated residues are shown, together with $1 \mathrm{D}$ slices at the positions of black horizontal and vertical lines. Blue lines in 2D planes from the VLP spectrum indicate positions of the corresponding crosspeaks in the CA tube spectrum, to facilitate comparisons of chemical shifts. Chemical shift differences are also indicated by differences in the 2D plane position in the third dimension, as shown in the upper left corner of each plane. Contour levels increase by successive factors of 1.4 . 

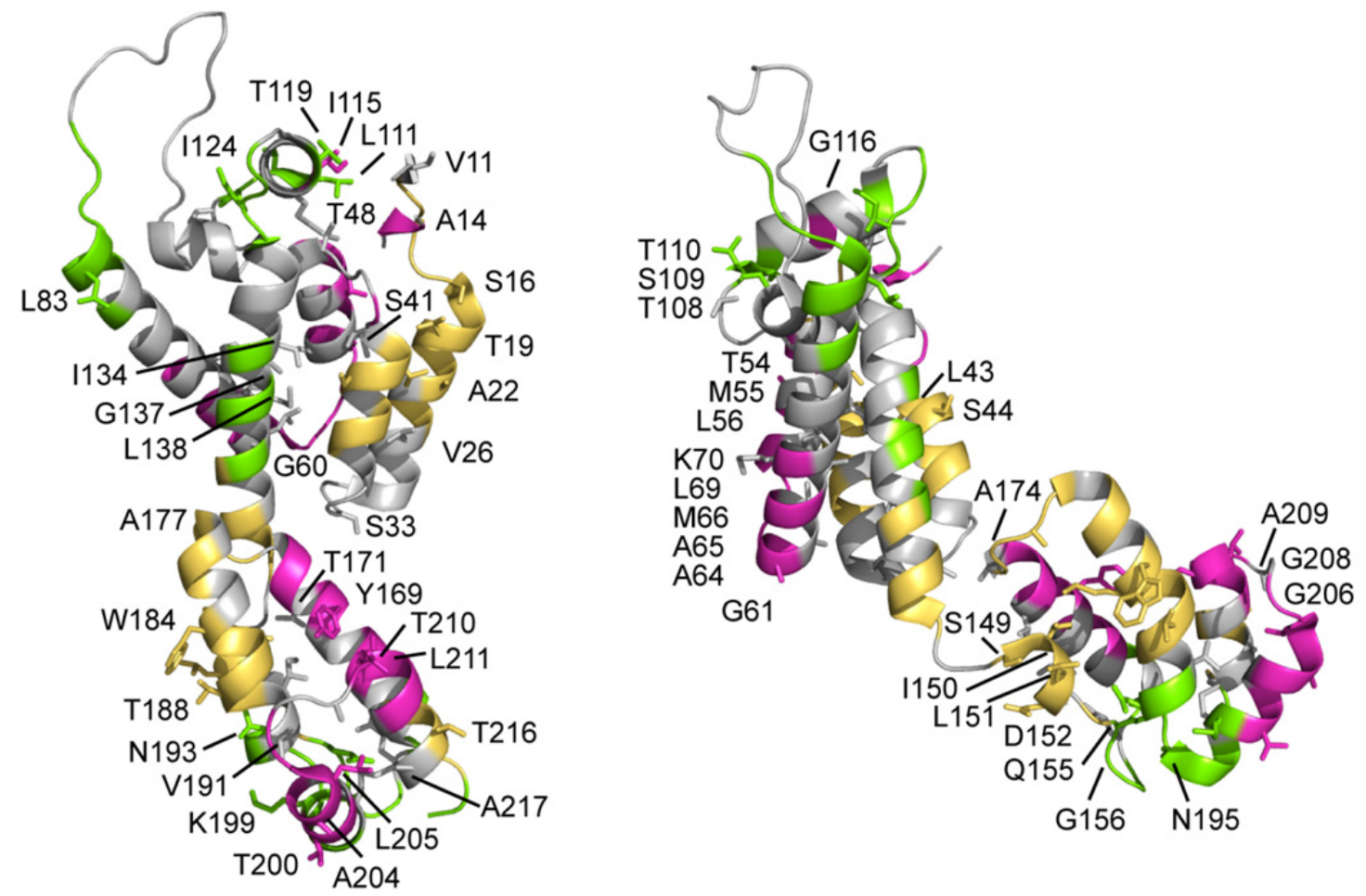

Figure S7. Mapping spectral changes to differences in mature and immature lattice interfaces. Orthogonal views of a CA monomer are colored according to their involvement in intermolecular interactions, with residues that make intermolecular contacts in the mature CA lattice (according to PDB 4XFX) colored pink, residues that make intermolecular contacts in the immature Gag lattice (according to PDB 4USN) colored green, and residues that make intermolecular contacts in both lattices (but not necessarily with the same partners) colored yellow. Residues with significant differences in the ssNMR spectra of CA tubes and $\triangle$ MA-CA-SP1-NC VLPs are labeled. These differences are also summarized in Fig. 4E of the main text. 